N87:-29126

$\sum_{\substack{\infty \\ 0}}^{\substack{0 \\ 0}}$

1
10
$I$
$z$
0
1
$\frac{1}{\Sigma}$

$\frac{1}{3}$

in

( $\infty$

$\sum_{i 11} \infty$

$\frac{\alpha}{0}$

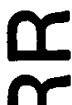

正

\& 6

co

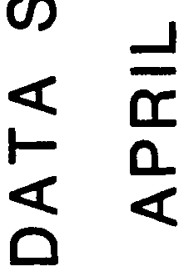

ш

0

嵌

$\overline{0}$

O

$\sum_{0}^{\frac{r}{w}}$ 

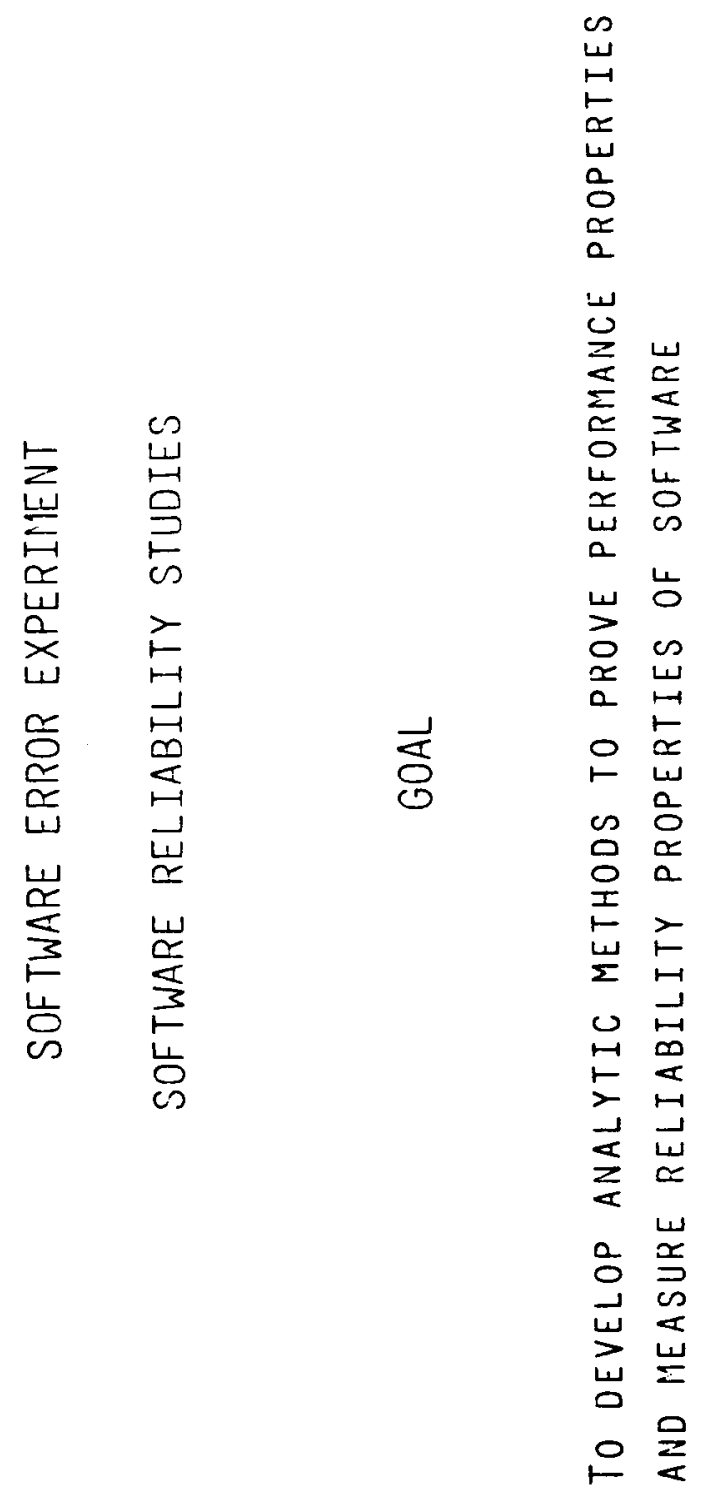


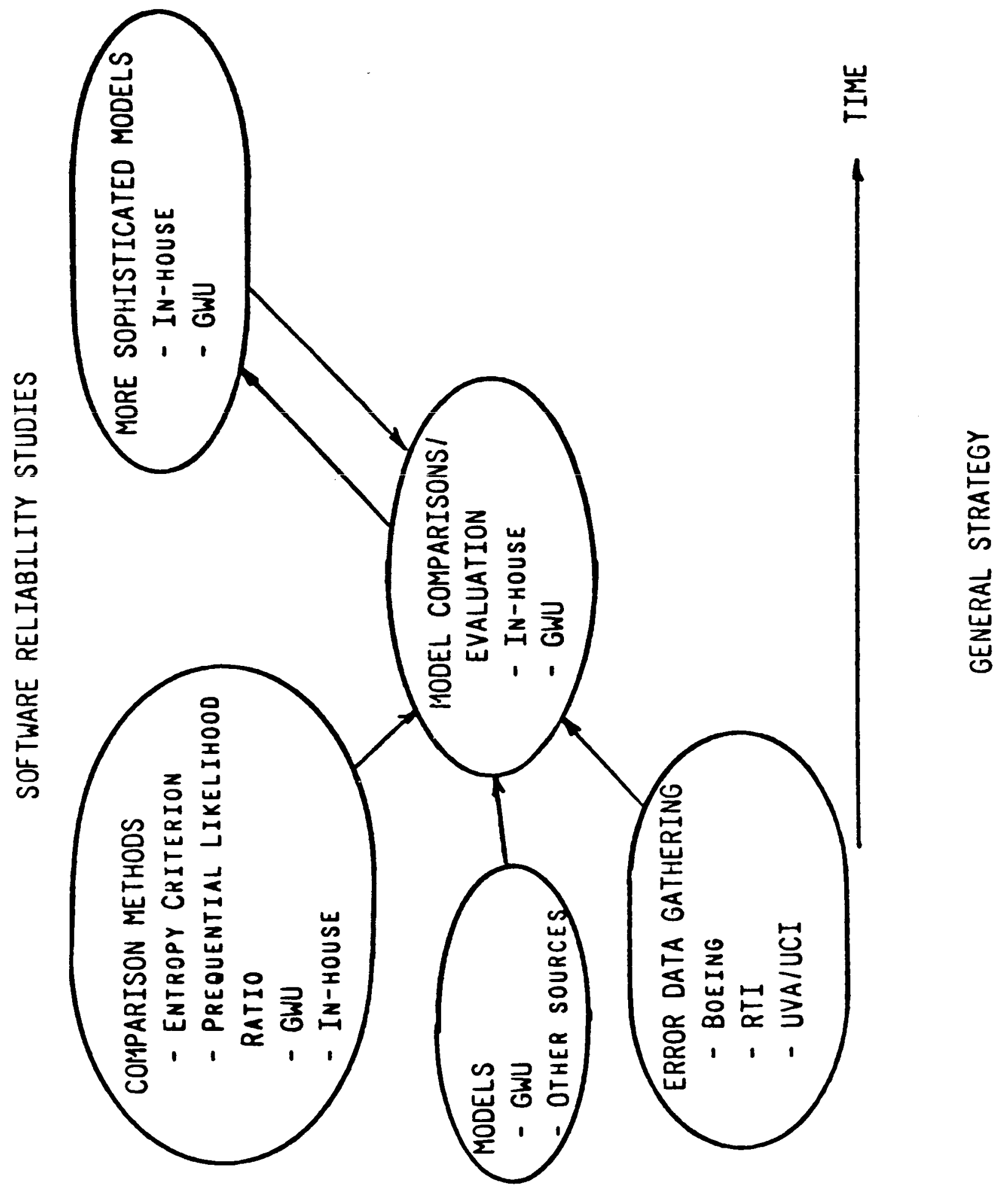




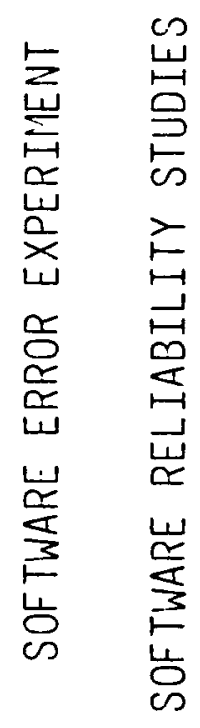

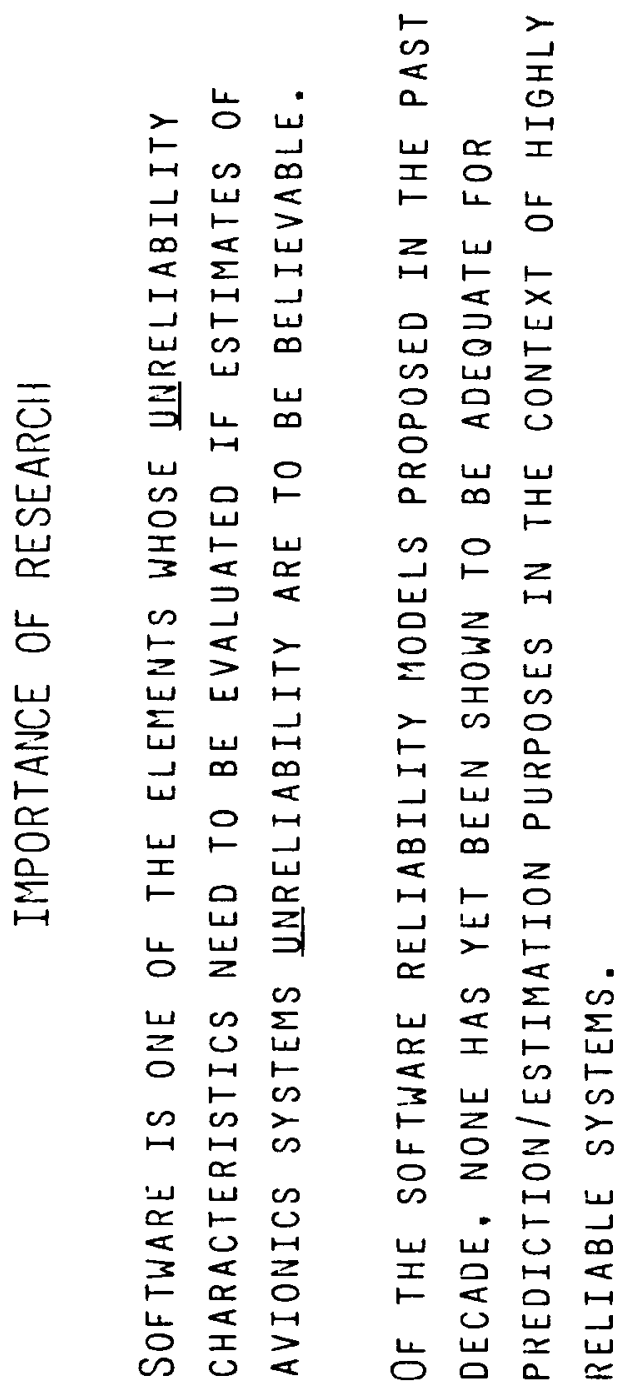




\section{SOFTWARE ERROR EXPERIMENT}

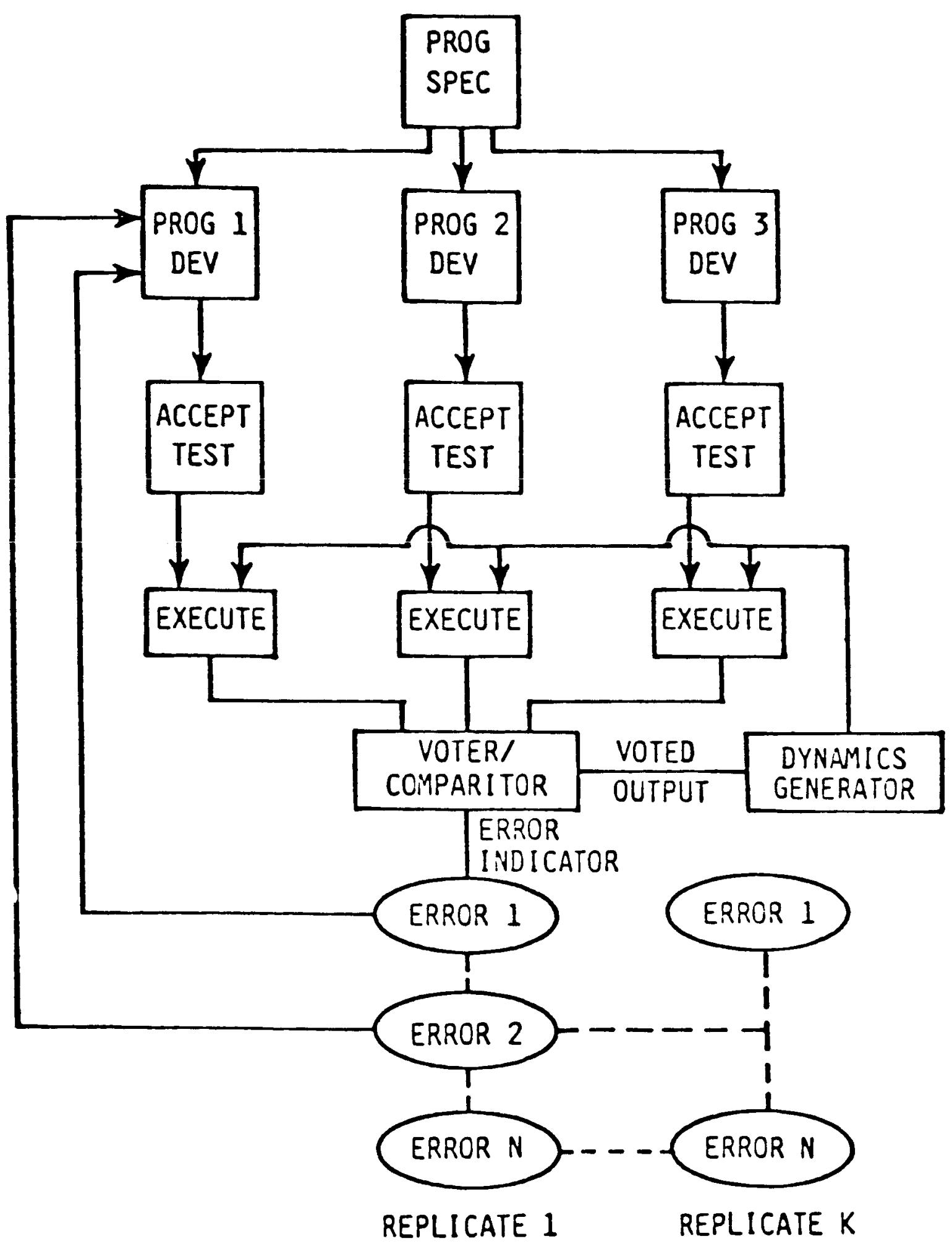




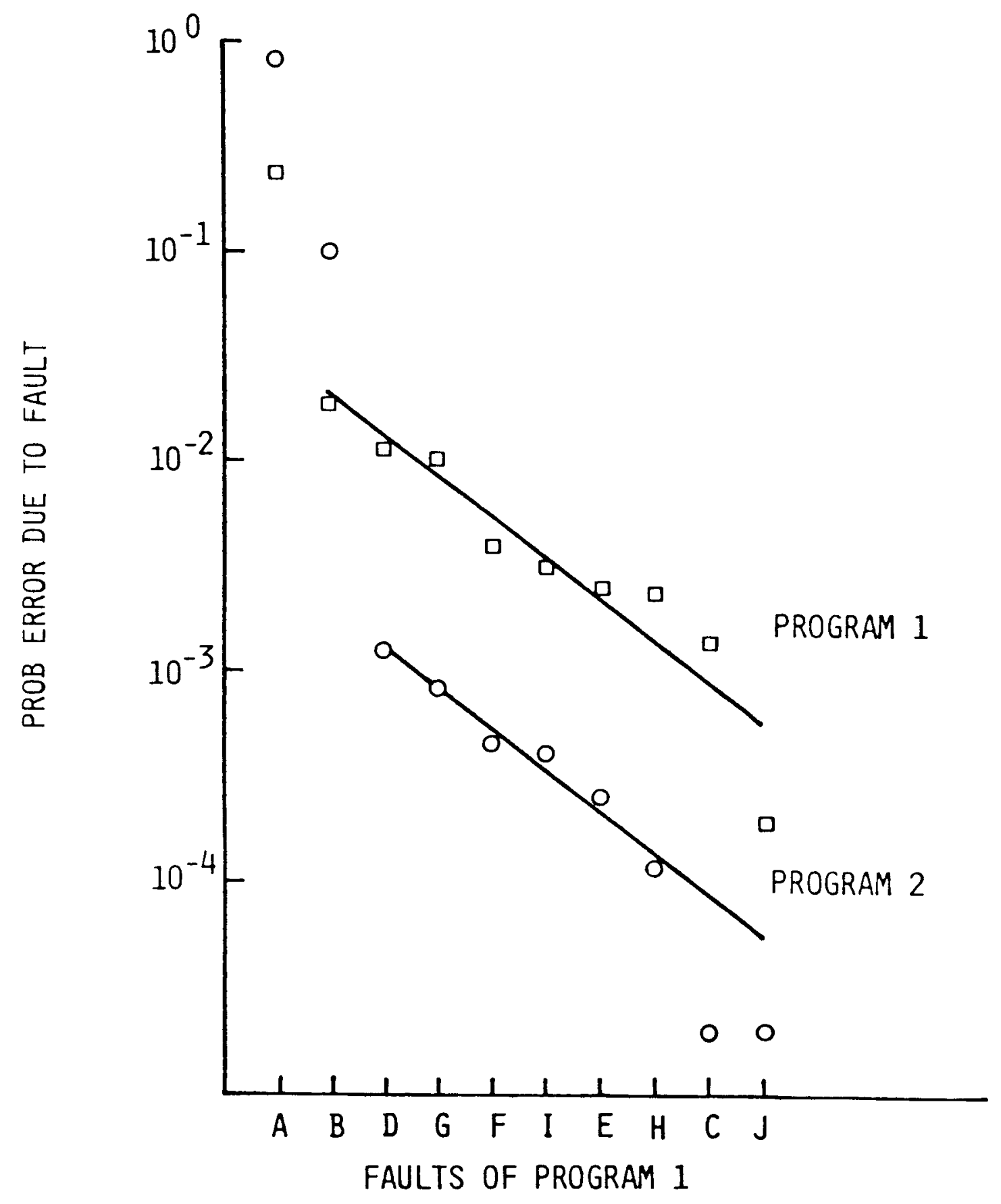

$B$ D A I $E$ D F G

FAULTS OF PROGRAM 2 

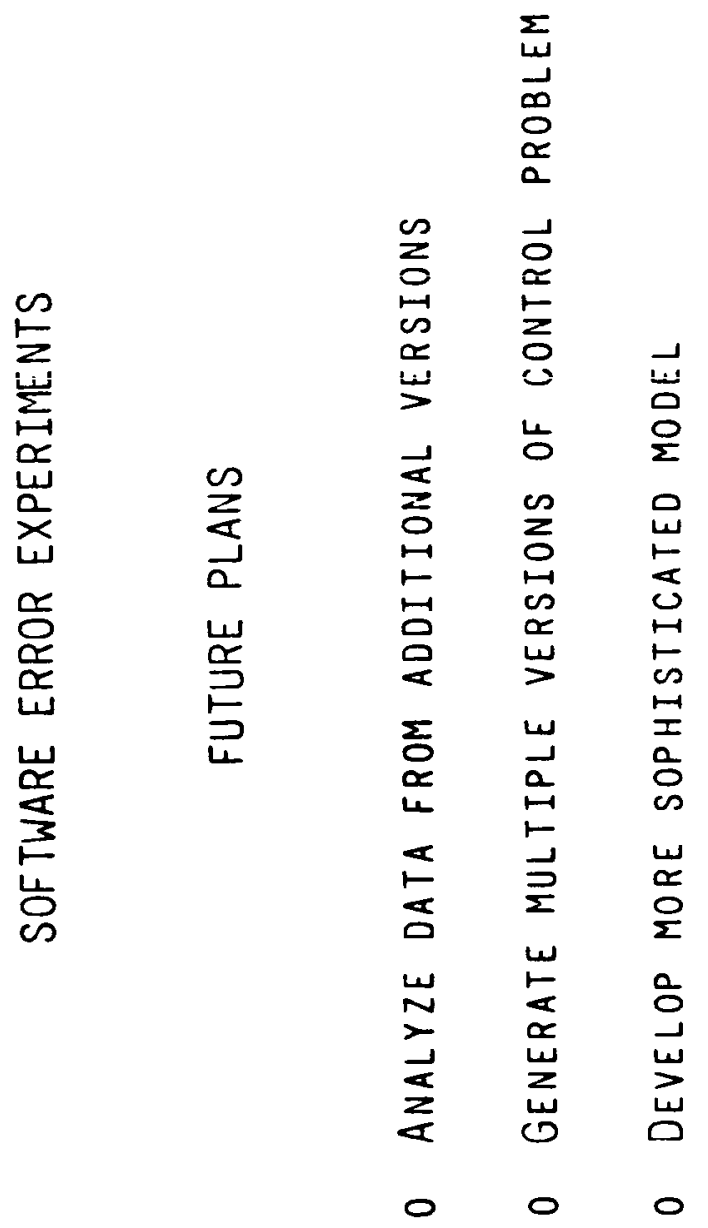